\title{
Cardiac troponin measured by a high-sensitivity assay in hypertensive patients
}

\author{
Jerzy Głuszek', Teresa Kosicka² \\ ${ }^{1}$ State Higher Vocational School in Kalisz \\ ${ }^{2}$ University of Medical Sciences
}

\begin{abstract}
Summary
Thanks to the rapid advances in laboratory techniques sensitive assays for measurement of cardiac troponin level have been recently introduced, and now is possible to determine ten-fold lower concentration of troponin in blood serum than the standard method used until now. The blood level of highly sensitive cardiac troponin in hypertensive patients is higher than in healthy persons, which may indicate increased necrosis or apoptosis of cardiac cells. Elevated high-sensitivity cardiac troponin concentration is an important risk factor for future cardiovascular complications independent of many co-existing contributing factors. In particular, elevated concentration of this troponin indicates the left ventricular hypertrophy and a tendency to develop heart failure. It has also been shown that elevated concentrations of high-sensitivity troponin are more common in non-dipper patients than in those with a normal circadian pattern of blood pressure. Few studies so far indicate that currently used antihypertensive therapy only slightly lower the increase concentration of those compounds in serum.
\end{abstract}

Key words: cardiac troponin, hypertensive patients

Arterial Hypertens. 2018, vol. 22, no. 3, pages: 107-112

DOI: $10.5603 / A H .2018 .0014$

Troponin $\mathrm{T}$ and troponin I are proteins present in cardiomyocytes. Cardiomyocyte necrosis causes these compounds to be released into the bloodstream. The concentration of both these troponins in blood serum has been used for a long time in clinical practice in diagnosis of myocardial infarction. Their levels, $0.03 \mathrm{ug} / \mathrm{L}$ for troponin $\mathrm{T}$ and $0.12-0.4 \mathrm{ug} / \mathrm{L}$ for troponin I (depending on the method of determination), indicate a myocardial infarction [1]. Increased troponin levels are highly sensitive and relatively specific compared to other laboratory parameters. Nevertheless, the increase in troponin levels has also been observed in sepsis, pulmonary embolism, severe heart failure and myocarditis.

Previously used, conventional methods of determination of troponin levels in blood serum detect concentrations of this compound in the blood with an accuracy of $0.01 \mu \mathrm{g} / \mathrm{L}$. Methods allowing ten times lower troponin concentrations, down to 0.001 $\mu \mathrm{g} / \mathrm{L}$, namely $1 \mathrm{ng} / \mathrm{L}$, to be detected have been developed during this decade. Currently, three pharmaceutical companies offer commercially available high-sensitivity cardiac troponin T testing kits. These are Abbott, Erenna and Roche.

A large meta-analysis by Willeit, including over 150,000 people, published a year ago showed that even troponin concentrations below $10 \mathrm{ng} / \mathrm{L}$ are of prognostic significance from the point of view of the subsequent development of cardiovascular diseases [2]. Troponin presence in blood serum was found in $80 \%$ of studied individuals, the average concentration of this compound was $7 \mathrm{ng} / \mathrm{L}$, and it did not exceed $14 \mathrm{ng} / \mathrm{L}$ in $95 \%$ of the participants. The high-sensitivity cardiac troponin $\mathrm{T}$

Address for correspondence: Dr n. med. Teresa Kosicka

tel.: 618549090, e-mail: tkosicka@poczta.fm 
method shows significant statistical correlation with participant age, systolic blood pressure, body mass, diabetes duration, cholesterol concentration, smoking, renal failure and concentration of the B-type natriuretic peptide (BNP). Ten years of observation of the participants also showed that high-sensitivity cardiac troponin $\mathrm{T}$ determined using a high-sensitivity method is a significant risk factor of heart failure and ischaemic heart disease, as well as of death.

In 2011, Setsuta published results of a 52-month observation of 176 patients with hypertension diagnosed at least 2 years earlier, in which he initially determined troponin $\mathrm{T}$ concentration in blood serum using a conventional method [3]. No symptoms of cardiovascular diseases were observed in any of these patients, in particular using electrocardiographic exertion tests and coronarography, which excluded chronic coronary heart disease, while echocardiographic examinations excluded hypertrophic cardiomyopathy and heart failure. Normal creatinine clearance was identified in all studied patients. In 15 patients, troponin concentration exceeded $0.02 \mathrm{ng} /$ $/ \mathrm{mL}$; in other patients the troponin concentration was below the detection limit. In patients with increased troponin levels, cardiovascular complications occurred already after a year of observation and were statistically more frequent $(\mathrm{p}<0.00001)$ at the end of the observation period.

High-sensitivity cardiac troponin $\mathrm{T}$ in patients with newly diagnosed hypertension was studied for the first time by Sato et al. in 236 patients with the average age of 65.5 years [4]. The average troponin concentration was $0.008 \mathrm{ng} / \mathrm{mL}$ in 184 patients. The concentration was below $0.003 \mathrm{ng} / \mathrm{mL}$ in other patients. Patient age, NT-proBNP concentration, amounts of hypotensive medication used and left ventricular hypertrophy determined by electrocardiography showed the positive correlation with high-sensitive troponin concentration. On the other hand, haemoglobin and eGFR concentrations correlated negatively.

Troponin concentration (high-sensitivity cardiac troponin T) may also be used as a marker of the increased tendency to developing hypertension in the future in previously healthy individuals. Studies by McEvoy et al., who determined high-sensitive troponin concentration in 6,516 participants of the ARIC study [5], indicate this fact. The study was initiated in 1990-1992 by collecting blood samples for determination of high-sensitivity cardiac troponin from individuals without hypertension and cardiovascular disease, and the onset of hypertension was recorded over the period of at least 6 to 20 years (19.9 years).
The initial troponin concentration below $5 \mathrm{ng} / \mathrm{L}$ was accepted as the reference value. In individuals with troponin concentration in the range of $5-8 \mathrm{ng} /$ $/ \mathrm{mL}$, the risk of hypertension development was low and estimated at 1.16. In individuals with the initial troponin levels of $9-13 \mathrm{ng} / \mathrm{m} / \mathrm{L}$ this risk was 1.29 , and it finally increased to 1.31 in individuals with troponin concentration above $14 \mathrm{ng} / \mathrm{mL}$ (the trend significance was $\mathrm{p}<0.001$ ). Left ventricular hypertrophy determined using electrocardiography was also significantly more frequent in individuals with high-sensitivity cardiac troponin $\mathrm{T}$ concentration over $14 \mathrm{ng} / \mathrm{mL}$ compared to the troponin level below $5 \mathrm{ng} / \mathrm{mL}$ (HR 5.19).

An evaluation of high-sensitivity cardiac troponin I was presented by Aeschbacher et al. in over 2,000 young, healthy people in the age group of 25-41 [6]. This troponin was detected in $99.5 \%$ of the studied individuals, and its concentration was $0.98 \mathrm{ng} / \mathrm{L}$ in males and $0.48 \mathrm{ng} / \mathrm{L}$ in females. The concentration of this troponin in blood serum was divided into quartiles. In the lowest quartile, the systolic blood pressure was $118 \mathrm{mmHg}, 120 \mathrm{mmHg}$ in the next quartile, the average pressure was $121 \mathrm{mmHg}$ in the third quartile and eventually increased to $122 \mathrm{mmHg}$ in the last quartile. Diastolic blood pressure had no significant influence on the concentration of the studied troponin. The authors also showed a significant correlation between left ventricular hypertrophy determined using electrocardiography (the Sokolov method) and the concentration of the studied troponin.

Even the concentration of high-sensitive troponin in individuals with prehypertension is different than troponin levels in healthy individuals. This was shown by Askin and Yesiltepe who determined high-sensitivity cardiac troponin T in 50 individuals with blood pressure in the range of 120/80-139/89 and in 50 healthy individuals of age and sex similar to the studied group, with blood pressure below 120/80 mm Hg [7]. Echocardiography was also performed in all studied individuals. The concentration of the studied troponin in the group of patients with prehypertension showed to be statistically higher than in healthy individuals $(\mathrm{p}<0.0001)$. Troponin concentration of $0.55 \mathrm{ng} / \mathrm{L}$ proved to be an indicator of prehypertension with a sensitivity of $86 \%$ and specificity of $60 \%(\mathrm{p}<0.001)$. The prehypertension defined as blood pressure of 120/80-139-89 occurs in nearly $30 \%$ of the population in our country. In many people, prehypertension gradually evolves to hypertension over the years. Because of the prevalence of prehypertension, results obtained by Askin and Yesiltepe are definitely noteworthy. 
An interesting relationship was also observed by Askin et al., between the levels of high-sensitivity cardiac troponin and the degree of nocturnal blood pressure drop in patients with primary hypertension [8]. A 24-hour ambulatory blood pressure monitoring (ABPM) was performed in 100 hypertensive individuals, with 63 of them displaying an appropriate drop of blood pressure during the night, and the remaining 37 individuals showing the nocturnal blood pressure drop lower than $10 \%$. The high-sensitivity cardiac troponin levels were significantly higher in non-dippers and showed high statistical correlation with the disrupted circadian blood pressure rhythm $(r=0.747, p>0.001)$. Similar observations were made by Cayli et al. who studied the blood pressure rhythms using the ABPM method in 317 patients with new-onset hypertension [9]. The troponin concentration was higher in non-dipper patients, and the cut-off index was $7.55 \mathrm{ng} / \mathrm{L}$. The authors of this study hold an opinion that the sensitivity and specificity of the method of non-dipper patient identification based on troponin measurements is $79 \%$ and $70 \%$, respectively $(\mathrm{p}<0.001)$.

Another author, Hitsumoto, reported a year ago that high-sensitivity cardiac troponin $\mathrm{T}$ shows significant correlation with the arterial velocity pulse index determined using the commercial device [10]. This author showed the presence of high-sensitivity cardiac troponin in $89 \%$ of hypertensive patients, and in patients with detectable levels of this troponin, the arterial velocity pulse index was 28 , while it was significantly lower and had a value of 24 in patients with undetectable troponin levels. The correlation between the high-sensitivity troponin level and the arterial velocity pulse index was $0.42, \mathrm{p}<0.001$. The arterial pulse wave velocity, which is increased in hypertension, is an arterial stiffness measure. Increased aortic stiffness may, in turn, accelerate damage to the left ventricle of the heart [11]. It is suspected that increased oxidative stress accompanying hypertension and increased blood vessel stiffness leads to apoptotic death of myocardial cells and heart failure. Studies potentially confirming the efficiency of anti-oxidative drugs in patients with increased troponin levels in the prevention of cardiovascular complications are thus suggested [12]. High-sensitivity cardiac troponin I level determined in blood serum correlates with peripheral blood pressure and central blood pressure values, as shown by Suigura et al., who studied these relationships in 1,210 participants of yearly health checkup program [13]. Central blood pressure and the augmentation index were determined in all patients using the tonometric method. The correlation between the central blood pressure and the troponin levels was higher in patients with large augmentation index values.

The prognostic significance of high-sensitivity cardiac troponins was also shown by American authors, who studied 11,191 participants of the Atherosclerosis Risk in Communities study [14]. The average patient age in the study was 63 ; the average blood pressure was $128 / 71 \mathrm{mmHg}$ (44\% of patients used hypotensive medication). The high-sensitivity troponin levels correlated with the age of the participants, NT-proBNP concentration, use of hypotensive drugs and indicators of left ventricular hypertrophy in the ECG examination. After 12-year observation, the number of cardiovascular complications was higher with increasing systolic blood pressure, as expected. However, the number of complications in every blood pressure range was the higher, the higher was the troponin concentration. Thus, in individuals with systolic blood pressure lower than $120 \mathrm{mmHg}$ and with troponin levels higher than $14 \mathrm{ng} / \mathrm{L}$, the risk of heart failure was 5 times higher than in individuals in the same blood pressure range and with troponin levels below $3 \mathrm{ng} / \mathrm{L}$. The risk of cardiovascular complications in patients with blood pressure of $150-160 \mathrm{mmHg}$ and troponin concentration $<3 \mathrm{ng} / \mathrm{L}$ was very close to the risk in individuals with the blood pressure of $120-130 \mathrm{mmHg}$ and troponin concentration of $8 \mathrm{ng} / \mathrm{L}$. The authors have also shown that individuals with serum troponin concentrations higher than $3 \mathrm{ng} / \mathrm{L}$ and with systolic blood pressure lower than $140 \mathrm{mmHg}$ had a higher risk of cardiovascular complications than patients with the systolic pressure in the range of 140-159 and with troponin levels below $3 \mathrm{ng} / \mathrm{L}$. The results of this work clearly show that the prognosis of cardiovascular complications depends not only on blood pressure but also on troponin concentration in blood serum [14].

Kaypakli et al. studied high-sensitivity cardiac troponin levels in 306 patients with diagnosed hypertension [15]. They showed that this concentration was higher in the patients with hypertension, in whom echocardiography showed left ventricular dysfunction or hypertrophy. A similar study was performed by Miao et al. whose observation included 537 patients with hypertension and without symptoms of ischaemic heart disease, as well as 100 healthy individuals of similar age and sex [16]. All patients were subjected to a precise echocardiographic examination, lipid and eGFR concentration determination. In $78 \%$ of patients with hypertension, troponin $\mathrm{T}$ levels higher than $3 \mathrm{pg} / \mathrm{mL}$ were detected and $30.7 \%$ of patients had troponin $\mathrm{T}$ level above $13 \mathrm{pg} / \mathrm{mL}$, a value significantly higher than in 
healthy individuals. The authors also showed a gradual significant increase in troponin levels depending on remodelling and hypertrophy of the left ventricle of the heart. Thus, in patients with hypertension and regular geometry of the left ventricle, troponin levels were $3.6 \mathrm{pg} / \mathrm{mL}$ and gradually increased in hypertensive subjects with concentric remodelling, concentring hypertrophy and eccentric hypertrophy. This correlation was independent of age, gender, fasting blood glucose and renal function.

Hypertension often leads to heart failure and, by accelerating atherosclerosis, to myocardial infarction. In patients with heart failure, the increase in high-sensitivity cardiac troponins is also a significant prognostic indicator of future cardiovascular complications, as well as of death. This is documented, among others, by the work of Graving et al. who determined baseline troponin levels in 1,245 patients aged 60 and older with heart failure [17]. It was shown after 3-year observation that in patients with baseline troponin concentrations higher than $14 \mathrm{ng} / \mathrm{L}$ heart failure occurred more frequently and was more severe, and cardiovascular and overall mortality rates were higher.

In 2018, Aimoi et al. published a meta-analysis related to the prognostic value of high-sensitivity cardiac troponin in patients with new-onset heart failure [18]. This meta-analysis included over 9,000 patients. Presence of high-sensitivity cardiac troponin $T$ was proven in all patients, and presence of troponin I in 209 studied individuals. It has been shown that troponin $\mathrm{T}$ concentration is a statistically significant and independent risk factor of hospitalization related to heart failure and cardiovascular death. The threshold level of troponin $\mathrm{T}$ above which this risk increased was $18 \mathrm{ng} / \mathrm{L}$.

Chronic ischaemic heart disease, caused, among others, by hypertension, is also characterised by increased troponin levels in blood serum. The median high-sensitive cardiac troponin concentration in 1,050 patients with chronic ischaemic heart disease was $10.9 \mathrm{ng} / \mathrm{L}$ in a study by Koening et al. [19]. During an 8-year observation, $14.3 \%$ of patients displayed secondary cardiovascular complications, and their emergence showed the statistical correlation with the initial troponin concentration $(\mathrm{HR}=2.83)$.

Troponin $\mathrm{T}$ is a protein binding tropomyosin, while troponin $I$ is an actin-binding protein and inhibits actin contact with myosin. Six to eight percent of troponins are present as free troponins in cellular cytoplasm. Troponin presence in blood serum is considered as a heart damage indicator [20]. It is suspected that apoptotic death of myocardial cells is caused by increased load, especially in hypertension, increased activity of the renin-angiotensin-aldosterone system and activation of the sympathetic nervous system, which may contribute to necrosis or increased permeability of cardiomyocyte cell membranes [21]. This is suggested by observations, which have shown significant relationships between blood troponin levels and the aforementioned factors [22]. Other authors suspect that oxidative stress, hypoxia and inflammatory cytokines are factors facilitating the apoptotic death of heart cells [23]. Thorough understanding of these factors accelerating apoptosis should enable development of new drugs inhibiting this process $[23,24]$.

Very few studies related to the influence of therapy on troponin levels have been published so far. It remains unknown whether lifestyle changes of healthy people with increased troponin concentrations may inhibit the further increase in the level of this compound in blood serum. The influence of hypotensive therapy on the level of high-sensitivity cardiac troponin was studied by Hoshide et al. [25] in 78 patients with hypertension. Half of these patients were treated with losartan and hydrochlorothiazide for 8 weeks, while the other half of the patients were treated with amlodipine. Blood pressure in both patient groups, evaluated using the ABPM method, decreased significantly. Troponin levels in the group treated with amlodipine decreased significantly $(\mathrm{p}<0.05)$, while it remained constant in the group treated with losartan and hydrochlorothiazide. These results are confirmed by previous experimental studies in which hypotensive therapy applied to rats, using inhibitors of angiotensin convertase and beta-blockers, produced an increment of apoptosis in parallel to cardiac hypertrophy regression whereas therapy using diuretics and hydralazine did not have any impact on the extent of apoptotic death of myocardial cells [23]. The impact of hypotensive therapy on the concentration of troponin I in the biggest patient group was described by Jagodziński et al. [26]. This study included 481 patients divided into two treatment groups, with the first one receiving a 6-month telmisartan therapy using a dose $80 \mathrm{mg}$ with $5 \mathrm{mg}$ of amlodipine, while the other half of the patients were treated with olmesartan using a dose of $40 \mathrm{mg}$ with $12.5 \mathrm{mg}$ of hydrochlorothiazide. Blood pressure decreased significantly from $135 / 85$ to $122 /$ $175 \mathrm{mmHg}$ in both patient groups. In the group using telmisartan/amlodipine, the levels of troponin I decreased from 4.6 to $4.0 \mathrm{ng} / \mathrm{L}$ ( $\mathrm{p}<0.001$ ), while in the olmesartan/hydrochlorothiazide sub-group a decrease from 4.7 to $4.4 \mathrm{ng} / \mathrm{L}(\mathrm{p}<0.001)$ was observed. At the same time, a comparable decrease in the BNP concentration was observed in both groups. 
Tunerir et al. obtained promising results, in double-blind trial in which they administered trimetazidine $60 \mathrm{mg} / \mathrm{day}$, orally, for three weeks before a CABG surgery [27]. The preoperative TnT concentration ranged from 0 to $0.39 \mathrm{ng} / \mathrm{mL}$. Then, the concentration of this troponin was measured 5 minutes after the surgery, as well as after 12, 24 and 48 hours. The troponin concentration in blood serum was significantly statistically lower $(\mathrm{p}<0.001)$ in all studied periods. Italian researchers also observed positive results of trimetazidine therapy. After a 6-month administration of this drug to a patient with chronic ischaemic heart disease, they observed significant improvement in the cardiac stress test combined with a significant decrease in troponin and BNP concentrations, contrary to the control group in which troponin concentration in blood serum remained unchanged, and the BNP level increased [28]. The results obtained by the authors cited above should be confirmed in future, large clinical tests.

The high-sensitivity cardiac troponin concentration in patients with hypertension is a novel, valuable risk factor related to cardiovascular diseases. Future studies shall likely show which hypertension treatment strategy is the most favourable in decreasing the elevated troponin levels and whether such therapies can decrease the cardiovascular risk in such patients.

\section{References}

1. Szczeklik A. Choroby Wewnętrzne. Medycyna Praktyczna, Kraków 2010.

2. Willeit P, Welsh P, Evans JDW, et al. High-Sensitivity Cardiac Troponin Concentration and Risk of First-Ever Cardiovascular Outcomes in 154,052 Participants. J Am Coll Cardiol. 2017; 70(5): 558-568, doi: 10.1016/j.jacc.2017.05.062, indexed in Pubmed: 28750699.

3. Setsuta K, Kitahara Y, Arae M, et al. Elevated cardiac troponin T predicts adverse outcomes in hypertensive patients. Int Heart J. 2011; 52(3): 164-169, indexed in Pubmed: 21646739.

4. Sato Y, Yamamoto E, Sawa T, et al. High-sensitivity cardiac troponin T in essential hypertension. J Cardiol. 2011; 58(3): 226-231, doi: 10.1016/j.jjcc.2011.07.009, indexed in Pubmed: 21885250.

5. McEvoy J, Chen Y, Nambi V, et al. High-Sensitivity Cardiac Troponin T and Risk of HypertensionCLINICAL PERSPECTIVE. Circulation. 2015; 132(9): 825-833, doi: 10.1161/circulationaha.114.014364.

6. Aeschbacher S, Schoen T, Bossard M, et al. Relationship between high-sensitivity cardiac troponin I and blood pressure among young and healthy adults. Am J Hypertens. 2015; 28(6): 789-796, doi: 10.1093/ajh/hpu226, indexed in Pubmed: 25424717.

7. Askin L, Yesiltepe Y. High-Sensitivity Cardiac Troponin T levels in prehypertensive patients. Clin Exp Hypertens. 2018; 40(4): 332-336, doi: 10.1080/10641963.2017.1377216, indexed in Pubmed: 28952796.

8. Askin L, Tasolar H, Aksu U, et al. Discerning the relationship between left ventricular geometry, high-sensitivity troponin $T$, and nondipper hypertension. Blood Press Monit. 2018; 23(1): 12-18, doi: 10.1097/MBP.0000000000000297, indexed in Pubmed: 29278556.

9. Çaylı M, Gür M, Elbasan Z, et al. High-sensitivity cardiac troponin $\mathrm{T}$ predicts nondipper hypertension in newly diagnosed hypertensive patients. J Clin Hypertens (Greenwich). 2013; 15(10): 731-736, doi: 10.1111/jch.12176, indexed in Pubmed: 24088281.

10. Hitsumoto T. Arterial Velocity Pulse Index as a Novel Marker of Atherosclerosis Using Pulse Wave Analysis on High Sensitivity Troponin T in Hypertensive Patients. Cardiol Res. 2017; 8(2): 36-43, doi: $10.14740 / \mathrm{cr} 545 \mathrm{w}$, indexed in Pubmed: 28515820.

11. Jaroch J, Rzyczkowska B, Bociąga Z, et al. The relationship of carotid arterial stiffness to left ventricular diastolic dysfunction in untreated hypertension. Kardiol Pol. 2012; 70(3): 223-231, indexed in Pubmed: 22430399.

12. Hitsumoto T, Shirai K. Factors affecting high-sensitivity cardiac troponin $\mathrm{T}$ elevation in Japanese metabolic syndrome patients. Diabetes Metab Syndr Obes. 2015; 8: 157-162, doi: $10.2147 /$ DMSO.S80907, indexed in Pubmed: 25792848.

13. Sugiura T, Dohi Y, Takase H, et al. Differential effects of brachial and central blood pressures on circulating levels of high-sensitivity cardiac troponin I in the general population. Atherosclerosis. 2018; 269: 185-191, doi: 10.1016/j.atherosclerosis.2018.01.015, indexed in Pubmed: 29366992.

14. Pokharel Y, Sun W, de Lemos JA, et al. High-sensitivity troponin $\mathrm{T}$ and cardiovascular events in systolic blood pressure categories: atherosclerosis risk in communities study. Hypertension. 2015; 65(1): 78-84, doi: 10.1161/HYPERTENSIONAHA.114.04206, indexed in Pubmed: 25350984.

15. Kaypakli O, Gür M, Gözükara MY, et al. Association between high-sensitivity troponin T, left ventricular hypertrophy, and myocardial performance index. Herz. 2015; 40(7): 1004-1010, doi: 10.1007/s00059-015-4322-3, indexed in Pubmed: 26087700.

16. Miao DM, Zhang LP, Yu HP, et al. Serum levels of high-sensitivity troponin T: a novel marker for left ventricular remodeling and performance in hypertensive subjects. Genet Mol Res. 2014; 13(3): 5143-5153, doi: 10.4238/2014.July.7.7, indexed in Pubmed: 25061739.

17. Gravning J, Askevold ET, Nymo SH, et al. CORONA Study Group. Prognostic effect of high-sensitive troponin T assessment in elderly patients with chronic heart failure: results from the CORONA trial. Circ Heart Fail. 2014; 7(1): 96-103, doi: 10.1161/CIRCHEARTFAILURE.113.000450, indexed in Pubmed: 24284025.

18. Aimo A, Januzzi JL, Vergaro G, et al. Prognostic Value of High-Sensitivity Troponin T in Chronic Heart Failure: An Individual Patient Data Meta-Analysis. Circulation. 2018; 137(3): 286-297, doi: 10.1161/ CIRCULATIONAHA.117.031560, indexed in Pubmed: 29335288.

19. Koenig W, Breitling LP, Hahmann H, et al. Cardiac troponin T measured by a high-sensitivity assay predicts recurrent cardiovascular events in stable coronary heart disease patients with 8-year follow-up. Clin Chem. 2012; 58(8): 1215-1224, doi: 10.1373/ clinchem.2012.183319, indexed in Pubmed: 22634379.

20. Korff S, Katus HA, Giannitsis E. Differential diagnosis of elevated troponins. Heart. 2006; 92(7): 987-993, doi: 10.1136/ hrt.2005.071282, indexed in Pubmed: 16775113.

21. Kociol RD, Pang PS, Gheorghiade M, et al. Troponin elevation in heart failure prevalence, mechanisms, and clinical implications. J Am Coll Cardiol. 2010; 56(14): 1071-1078, doi: 10.1016/j. jacc.2010.06.016, indexed in Pubmed: 20863950.

22. Moliner P, Lupón J, Barallat J, et al. TTM study group, ADHERE Investigators. Evaluation of incidence, clinical significance, and prognostic value of circulating cardiac troponin I and T elevation in hemodynamically stable patients with suspected myocardial contusion after blunt chest trauma. J Trauma. 2000; 48(5): 924-931, indexed in Pubmed: 10823538.

23. Fortuño MA, Ravassa S, Fortuño A, et al. Cardiomyocyte apoptotic cell death in arterial hypertension: mechanisms and potential management. Hypertension. 2001; 38(6): 1406-1412, indexed in Pubmed: 11751726.

24. Yue TL, Ohlstein EH, Ruffolo RR. Apoptosis: a potential target for discovering novel therapies for cardiovascular diseases. Curr 
Opin Chem Biol. 1999; 3(4): 474-480, doi: 10.1016/S13675931(99)80069-6, indexed in Pubmed: 10419841.

25. Hoshide S, Fukutomi M, Eguchi K, et al. Change in high-sensitive cardiac troponin T on hypertensive treatment. Clin Exp Hypertens. 2013; 35(1): 40-44, doi: 10.3109/10641963.2012.689044, indexed in Pubmed: 22631049.

26. Jagodzinski A, Neumann JT, Ojeda F, et al. Cardiovascular Biomarkers in Hypertensive Patients with Medical Treatment-Results from the Randomized TEAMSTA Protect I Trial. Clin Chem. 2017; 63(12): 1877-1885, doi: 10.1373/clinchem.2017.275289, indexed in Pubmed: 28904053.
27. Tünerir B, Colak $\mathrm{O}$, Alataş $\mathrm{O}$, et al. Measurement of troponin $\mathrm{T}$ to detect cardioprotective effect of trimetazidine during coronary artery bypass grafting. Ann Thorac Surg. 1999; 68(6): 2173-2176, indexed in Pubmed: 10616997.

28. Di Napoli P, Di Giovanni P, Gaeta MA, et al. Beneficial effects of trimetazidine treatment on exercise tolerance and B-type natriuretic peptide and troponin T plasma levels in patients with stable ischemic cardiomyopathy. Am Heart J. 2007; 154(3): 602. e1-602.e5, doi: 10.1016/j.ahj.2007.06.033, indexed in Pubmed: 17719313 . 